\title{
Epidemiology of the Global Fibrodysplasia Ossificans Progressiva (FOP) Community
}

\author{
Moira Liljesthröm', Robert J. Pignolo², Frederick S. Kaplan ${ }^{3 *}$ \\ 'President of Fundación FOP, Argentina; Argentine Representative to the International President's Council of the International Fibrodysplasia Ossificans Progres- \\ siva Association (IFOPA), Buenos Aires, Argentina \\ 2Department of Medicine, Mayo Clinic College of Medicine, Mayo Clinic, Rochester, MN 55905, USA \\ ${ }^{3}$ The Departments of Orthopaedic Surgery, Medicine and The Center for Research in FOP \& Related Disorders, The Perelman School of Medicine of The Univer- \\ sity of Pennsylvania, Philadelphia, PA 19104, USA
}

Article Info

\section{Article Notes}

Received: August 25, 2020

Accepted: September 28, 2020

\section{*Correspondence:}

Frederick S. Kaplan, Isaac \& Rose Nassau Professor of

Orthopaedic Molecular Medicine, Perelman School of Medicine,

The University of Pennsylvania, c/o Department of Orthopaedic

Surgery; Penn Musculoskeletal Center - Suite 600, 3737 Market

Street, Philadelphia, PA 19104. USA; Telephone No: 215-294-

9145; Fax No: 215-222-8854

Email: frederick.kaplan@uphs.upenn.edu

(C) 2020 Kaplan FS. This article is distributed under the terms of the Creative Commons Attribution 4.0 International License.

\section{Keywords:}

fibrodysplasia ossificans progressiva (FOP)

epidemiology

heterotopic ossification

prevalence

rare disease

patient organization

\section{ABSTRACT}

Background: Fibrodysplasia Ossificans Progressiva (FOP) is an ultrarare disease, but the geographic distribution and regional prevalence of the condition are unknown. This study was undertaken to determine the emerging global population of FOP patients who were associated with a regional, national or international FOP organization.

Results: This study interrogated the patient registration database of the International Fibrodysplasia Ossificans Progressiva Association (IFOPA) and those of the 16 regional or national FOP organizations in order to assemble a non-redundant worldwide census of patients living with FOP in 2016 who were associated with a pre-identified FOP community. The total registered population of the global FOP community was 834 individuals [ 445 females (54\%), 387 males (46\%), 2 unassigned] distributed in 67 countries and six continents. The apparent prevalence of registered and confirmed FOP patients varied substantially from approximately 0.65 per million in North America, 0.47 per million in Western Europe, and 0.27 per million in Latin America, to 0.05 per million in Africa and nearly 0.04 per million in the Asia-Pacific region.

Conclusions: The high variability in apparent prevalence is likely associated with lack of awareness of FOP in under-represented medical communities, delay in achieving the correct FOP diagnosis, lack of supporting regional infrastructure and inability of individuals with FOP to reach a local FOP organization or the international FOP community. Emerging knowledge of the apparent prevalence of FOP can serve as a catalyst for resource allotment; physician, patient and community education and outreach; clinical trial recruitment and global networking to achieve a more globally robust and interconnected FOP community.

\section{Abbreviation}

Fibrodysplasia ossificans progressiva (FOP), International Fibrodysplasia Ossificans Progressiva Association (IFOPA), heterotopic ossification (HO), activin receptor A, type I (ACVR1), bone morphogenetic protein (BMP), International Presidents Council on FOP (IPC), International Clinical Council on FOP (ICC).

\section{Background}

Fibrodysplasia ossificans progressiva (FOP; MIM\#135100) is a progressively disabling genetic disorder which leads to the formation of a second skeleton of heterotopic bone ${ }^{1,2}$. Individuals with FOP appear normal at birth except for characteristic malformations of the great toes that are present in all classically affected individuals ${ }^{1}$. 
During the first decade of life, episodic soft tissue swellings (or flare-ups) can arise in the neck and back and mature into heterotopic bone ${ }^{3-5}$. Minor trauma such as intramuscular immunizations, mandibular blocks for dental work, muscle fatigue, blunt muscle trauma, bumps, bruises, falls, or influenza-like viral illnesses can trigger new flare-ups of FOP leading to progressive heterotopic ossification (HO) ${ }^{1}$. Flare-ups are episodic, but disability is cumulative ${ }^{4-6}$. Most patients are confined to a wheelchair or immobilized in a standing position by the third decade of life, and require lifelong assistance with activities of daily living $4,5,7,8$. The estimated median lifespan is 56 years; death often results from complications of thoracic insufficiency syndrome ${ }^{9}$.

Heterozygous missense mutations in activin receptor $A$, type I (ACVR1), a bone morphogenetic protein (BMP) type I receptor, were identified in all affected individuals ${ }^{10,11}$. Most cases of FOP are sporadic, but inheritance can occur by autosomal dominant transmission ${ }^{11-13}$. The mutation causes loss of autoinhibition of ACVR1 and renders it susceptible to dysregulated signaling through the BMP pathway ${ }^{1,14,15}$.

Standard-of-care medical management is based on prevention of complications and is currently supportive 16. Definitive treatments and cures are not yet available. There is a critical unmet need for targeted therapies many of which show promise in pre-clinical studies ${ }^{17}$. The discovery of the FOP gene and emerging insights into its mechanism of action has led to current and upcoming clinical trials $\left(\right.$ see $^{18}$ ).

Despite the promise for the future ${ }^{19}$ and the social connectivity of those who are known to have FOP ${ }^{20}$, there are likely many who are yet unidentified or unconnected to a viable FOP network. The rarity of FOP, the absence of local support groups in various regions of the world, the general lack of awareness of FOP among medical professionals, the alarming rate of misdiagnosis ${ }^{21}$ and the present lack of definitive treatments amplify the isolation of those living with this progressively disabling condition and hamper access of unidentified individuals to medical services, social support and emerging clinical trials ${ }^{19}$.

Although there appears to be no gender, racial or ethnic bias to FOP ${ }^{11}$, little is currently known about the regional global distribution of patients with FOP. We undertook this study to determine the worldwide distribution of patients with FOP who were associated with a pre-established FOP network to help identify regions of the world where greater efforts need to be expended to serve the needs of as yet unidentified patients.

Methods

\section{Ascertainment of individuals with FOP}

To achieve the baseline goal of accurately determining the number and geographic distribution of individuals registered or associated with FOP organizations throughout the world, the principal investigator (ML) reviewed existing databases of the International Presidents Council (IPC), the International Fibrodysplasia Ossificans Progressiva Association (IFOPA) and the respective 16 regional and national FOP associations worldwide (Argentina \& Latin America, Australia, Brazil, Canada, China, Italy, Malaysia, Netherlands, Poland, Russia, Scandinavia, Serbia, South Africa, Spain, United Kingdom, United States) to assemble an anonymous and non-redundant census of expert physician-confirmed FOP patient-members who were alive in January, 2016. The anonymous data requested for each individual registrant with FOP was: year of birth, country of birth, gender and country of residence. When more than one information source existed for a country, databases were harmonized and reconciled by the principal investigator (ML) to exclude redundancy. Control population data were obtained from contemporaneous United Nations sources ${ }^{22}$. We refer to the "global" or "worldwide" distribution of FOP patients as those in the 67 countries and 6 continents represented by regional and national FOP associations.

The workflow of the study was composed of three iterative phases: 1) identification of individuals who were alive in 2016 and have clinically and/or molecularly confirmed FOP in the 17 databases, 2) harmonization of the databases to exclude redundancy, and 3) confirmation of FOP cases by an FOP expert from a regional medical network or from the 21 members of the International Clinical Council on FOP (ICC) ${ }^{23}$. All patients recorded in the regional databases were diagnosed as having FOP by expert physicians, meaning that they were seen at least once in regional, national or international FOP clinics, and they were diagnosed either by clinical-radiological hallmarks and/or by molecular testing, available since 2006. Thus patients included in the 17 databases were considered to be true FOP patients associated with a regional, national or international FOP network.

\section{Statistical Analysis}

Our analysis included an iterative method to ascertain the apparent prevalence and geographic distribution of individuals with clinically and/or molecularly confirmed FOP and who were registered or associated with predetermined regional, national or international FOP organizations. The apparent prevalence was calculated by dividing the number of living individuals with FOP by the respective resident population(s) obtained from contemporaneous United Nations sources ${ }^{22}$.

\section{Results}

The total known and clinically confirmed population of the worldwide FOP community associated with a regional, national or international network of individuals with FOP 
Table 1: Apparent prevalence of FOP by region in the global FOP community

\begin{tabular}{|l|c|c|c|}
\hline \multicolumn{1}{|c|}{ Region } & Number of countries & Individuals with FOP & Apparent Prevalence (per 10 \\
\hline North America & 2 & 231 & 0.6465 \\
\hline Oceania & 2 & 15 & 0.5285 \\
\hline Western Europe & 17 & 198 & 0.4735 \\
\hline Eastern Europe & 13 & 87 & 0.3048 \\
\hline Latin America & 15 & 161 & 0.2758 \\
\hline Africa & 4 & 10 & 0.0520 \\
\hline Asia/Pacific & 14 & 132 & 0.0355 \\
\hline Totals & 67 & 834 & 0.1494 \\
\hline
\end{tabular}

in 2016 was 834 individuals [445 females (54\%), 387 males (46\%), gender not reported for two individuals] distributed in 67 of the world's 193 countries (35\%). The 67 countries of the international FOP community were grouped in the following seven regions of the world: North America (Canada, United States); Latin America (Argentina, Bolivia, Brazil, Chile, Columbia, Cuba, Ecuador, Guatemala, Honduras, Mexico, Panama, Paraguay, Peru, Uruguay, Venezuela); Western Europe (Austria, Belgium, Denmark, Finland, France, Germany, Greece, Ireland, Italy, Malta, Norway, Portugal, Netherlands, Spain, Switzerland, Sweden, United Kingdom); Eastern Europe (Armenia, Belorussia, Bosnia-Herzegovina, Croatia, Estonia, Georgia, Macedonia, Moldova, Poland, Romania, Russia, Serbia, Ukraine); Africa (Egypt, Libya, South Africa, Sudan); Asia-Pacific (Bangladesh, China \& Taiwan, Hong Kong, India, Indonesia, Iran, Israel, Japan, Kazakhstan, Malaysia, North Korea, Pakistan, South Korea, Turkey) and Oceania (Australia, New Zealand). The greatest number of people living with FOP were located in North America (231/834; 28\%), followed by Western Europe (198/834; 24\%), Latin America (161/834; 19\%), Asia-Pacific (132/834; 16\%), Eastern Europe (87/834;10\%), Oceania $(15 / 834 ; 2 \%)$ and Africa $(10 / 834 ; 1 \%)$.

The prevalence of FOP in each of the seven regions (expressed as the number of known individuals living with FOP in each region divided by the total population and adjusted per million individuals) varies substantially from approximately 0.65 per million in North America, 0.47 per million in Western Europe, and 0.27 per million in Latin America to 0.05 per million in Africa and nearly 0.04 per million in the Asia-Pacific region (Table 1).

The estimated prevalence often quoted for FOP is 0.5 per million individuals. However, our data reveal that 13 of the 67 countries of the FOP community have an apparent prevalence (prevalence based on currently available patients with confirmed FOP) that is higher than the estimated one. Thirteen countries (Sweden, Finland, Denmark, United Kingdom, Norway, United States, Poland, Chile, Argentina, Australia, Canada, Netherlands, and Italy) have an apparent prevalence of over 0.5 per million inhabitants (Table 2).
Table 2: Countries with the highest apparent prevalence of FOP

\begin{tabular}{|l|c|}
\hline \multicolumn{1}{|c|}{ Country } & $\begin{array}{c}\text { Apparent Prevalence } \\
\text { (per 106 }\end{array}$ \\
\hline Sweden & 1.428 \\
\hline Finland & 1.098 \\
\hline Denmark & 0.877 \\
\hline United Kingdom & 0.877 \\
\hline Norway & 0.769 \\
\hline United States & 0.658 \\
\hline Poland & 0.633 \\
\hline Chile & 0.613 \\
\hline Argentina & 0.599 \\
\hline Australia & 0.588 \\
\hline Canada & 0.559 \\
\hline Netherlands & 0.532 \\
\hline Italy & 0.526 \\
\hline
\end{tabular}

Table 3: Decadal distribution of individuals in the global FOP community

\begin{tabular}{|l|c|c|}
\hline Age range (years) & Individuals with FOP & Percentage \\
\hline $0-9$ & 97 & 11.6 \\
\hline $10-19$ & 194 & 23.3 \\
\hline $20-29$ & 209 & 25 \\
\hline $30-39$ & 133 & 15.9 \\
\hline $40-49$ & 89 & 10.7 \\
\hline $50-59$ & 47 & 5.6 \\
\hline $60-69$ & 13 & 1.6 \\
\hline $70-79$ & 4 & 0.5 \\
\hline No data & 48 & 5.8 \\
\hline Totals & 834 & 100 \\
\hline
\end{tabular}

Most individuals living with FOP (722/834; 87\%) were alive in the first five decades (0-49 years of age) of their lives (Table 3). The largest percentage were individuals in the third decade of life $(209 / 834 ; 25 \%)$ followed by those in the second decade of life $(194 / 834 ; 23.3 \%)$.The relatively low number of individuals with FOP in the first decade of life $(11.6 \%)$ is likely due to onset variability, delay in diagnosis and/or delay in reaching an established FOP organization (Table 3).

\section{Discussion}

Community was an important concept in our study. 
Unlike other studies of apparent prevalence in FOP, our goal was to determine the number of true FOP patients who were associated with a regional, national or international FOP organization so that worldwide discrepancies in patient access to information, medical and social services and clinical trials could be more easily identified and remedied ${ }^{24,25}$.

Our study documents a clinically confirmed worldwide population of 834 individuals with FOP who are associated with a regional, national or international FOP organization. This establishes a global apparent prevalence of approximately 0.15 per million individuals with enormous regional variability. The apparent global prevalence of FOP is more than three-fold lower than that previously estimated based on high ascertainment rates in circumscribed national populations ${ }^{13,26-28}$. This low apparent global prevalence and high regional variability is likely associated with lack of awareness of FOP in underrepresented regions, delay in achieving the correct FOP diagnosis, lack of supporting regional infrastructure to patients and families and inability of individuals with FOP in remote or underserved areas to reach the international FOP community. Although these dramatic differences could be caused by lack of awareness of FOP in under-represented medical communities, it might also point out the possible effects of different genetic backgrounds or environmental factors which might affect the activity of mutated ACVR1 and thus penetrance of the phenotype.

If we hypothesize that all regions could attain the same level of ascertainment and apparent prevalence as the one estimated for Western Europe ( 0.47 per million) or North America ( 0.65 per million), we surmise the number of missing cases of FOP worldwide to be between 1800 to 2800 based on a population of around 5.5 billion for the countries included in the study (for the year 2015) and between 2600 and 4000 based on the total world population of more than seven billion people at the same time. Thus, a large proportion of those likely living with FOP are presently unaccounted for in the already-established regional, national and/or international FOP organizations. This estimation, based on regional ascertainment and apparent prevalence rates, may spearhead efforts to identify missing individuals in those regions with already established FOP organizations and promote support for the emergence of new FOP organizations in those countries and regions of the world where individuals with FOP are likely isolated, without support or information.

There are several caveats and limitations of this study worthy of note. First, the study only accounted for FOP patients who were registered with a regional, national and/or international FOP organization. Although most people from the FOP community find great benefits in being part of it, there are others with FOP who likely chose to remain isolated despite knowing the existence of FOP organizations.

Second, the data reported here are apparent prevalence rather than true prevalence since the global sources for data acquisition are still scarce and reflect bias of ascertainment. However, the apparent prevalence data reported here may provide a valuable snapshot of emerging FOP populations along with suggestions about the number of individuals with FOP that might be found in countries or regions with little or no organizational support structure. China, Italy, Poland, Russia, South Africa and Spain serve as instructive examples of countries that had no regional or national infrastructure in place prior to 2006 for reporting known FOP cases or estimating apparent prevalence data. The FOP gene discovery in 2006 focused attention on FOP and stimulated concerted efforts of committed families and physicians in each of the countries mentioned above to organize a vibrant local community to contribute to emerging representation in the global FOP community ${ }^{27,29}$. We anticipate that emergence of established and effective treatments will have a similar mobilization effect on identification of additional patients in the global FOP community.

Third, there are other methodologies that can be used to attain epidemiologic data on the prevalence of FOP. As an example, while this study was being conducted, an independent inquiry using an entirely different methodology and rationale was being conducted in France ${ }^{26}$. Unlike our study, the goal of the French study was to estimate the true prevalence of FOP in France by probabilistic record-linkage of two anonymous national databases using a well-established capture-recapture approach. Eighty-nine FOP patients were identified across France, resulting in an estimated prevalence of 1.36 per million inhabitants ${ }^{26}$. Thus, unlike in our study, the ultimate goal was different and screening for false positives was necessary. In contrast, all patients in our study had a confirmed clinical and/or molecular diagnosis of FOP. Thus filters to detect false positives when anonymous databases of generic rare diseases or medical insurance data are used were unnecessary ${ }^{24-26}$.

Fourth, after we conducted this study, the IFOPA launched The FOP Connection Registry, an international, voluntary, observational study that directly captures demographic and disease information from patients with FOP. The guiding vision was to develop one unified, global registry allowing the assembly of comprehensive data on FOP that will facilitate development of therapies and tracking of their long-term treatment effectiveness and safety. Patient-reported, aggregate data from 196 enrolled patients represent participation from 42 countries and approximately $25 \%$ of the world's known FOP population and promises to add important demographic information to the emerging epidemiologic data worldwide ${ }^{30}$. 
The data from this study strongly suggest that sophisticated health systems with well-developed patient and community outreach facilitate prompt FOP diagnosis, promote active FOP community leaders who search for patients, and seem to be the major factors for achieving greater ascertainment of FOP patients while building a vibrant FOP community. In those regions where there are few patients affiliated with a patient organization, efforts are underway to promote FOP awareness and the search for undiagnosed individuals with FOP. For example, the global search for individuals with FOP, especially in developing nations, has recently been given international attention by the acclaimed documentary Tin Soldiers ${ }^{31}$.

\section{Conclusions}

Emerging knowledge of the regional apparent prevalence of FOP can serve as a catalyst for resource allotment; physician, patient and community education and outreach; clinical trial recruitment and global networking to develop a more globally inter-connected FOP community.

\section{Competing interests}

The authors declare that they have no competing interests.

\section{Authors' contributions}

ML conceived, designed and executed the study. ML \& FSK wrote the manuscript. All authors interpreted the data, revised and approved the manuscript.

\section{Acknowledgements}

We thank the following individuals, (many of them members with ML, the principal investigator) in the International President's Council of the International Fibrodysplasia Ossificans Progressiva Association (IFOPA) who voluntarily and generously contributed regional data to this report : Massimo Alfieri (Italy); Chris Bedford Gay (U.K.); Mihail Belyaev (Russia); Amanda Cali (USA); Julie Collins (Australia); Carrie Connell (Canada); Enrico Cristoforetti (Italy); Dr. Patricia Delai (Brazil); Vladislav Grachev (Russia); Marie Hallbert (Sweden); Juliana Louise (Malasya); Victoria Mandracken (USA); Patricia Marin (Spain); Jelena Milosevic (Serbia); Dr Antonio Morales Piga (Spain); Tomasz Przybysz (Poland); Dr Christiaan Scott (South Africa); Irene Snidjer (Netherlands) and Dr Keqin Zhang (China). We thank the following FOP organizations for participating in this project: The International FOP Association (IFOPA), Fundación FOP (Argentina \& Latin American Countries); FOP Brazil; Canadian FOP Network, South African FOP Association; AEFOP (Spain), FOP Italia, Friends of FOP (UK), FOP Stichting Nederland, FOP Skandinaviska, FOP Russia (Russia \& some nations of the former Soviet Union), FOP Australia, along with the leaders of Poland, Serbia, China and Malaysia. The authors thank Mr. Robert Caron and Mrs. Kamlesh Rai for their invaluable technical and administrative assistance.

\section{Funding}

This work was supported in part by the generous contributions of the IFOPA, the Center for Research in FOP and Related Disorders, the Ian Cali Endowment for FOP Research, the Whitney Weldon Endowment for FOP Research, the Robert and Arlene Kogod Professorship in Geriatric Medicine (to RJP), the Radiant Hope Foundation (to RJP) and the Isaac and Rose Nassau Professorship of Orthopaedic Molecular Medicine (to FSK). One of the authors (ML) declares that the work she contributed to this report was on a completely voluntary basis (i.e., without any direct support).

\section{References}

1. Kaplan FS, Pignolo RJ, Al Mukaddam M, Shore EM. Genetic disorders of heterotopic ossification: fibrodysplasia ossificans progressiva and progressive osseous heteroplasia. In: Bilezikian JP, ed. Primer on the Metabolic Bone Diseases and Disorders of Mineral Metabolism - Ninth Edition. Washington, D.C.: The American Society for Bone and Mineral Research, Washington; 2019:865-870.

2. Pignolo RJ, Shore EM, Kaplan FS. Fibrodysplasia ossificans progressiva: diagnosis, management, and therapeutic horizons. Pediatr Endocrinol Rev. 2013;10 Suppl 2:437-448.

3. Kaplan FS, Tabas JA, Gannon FH, Finkel G, Hahn GV, Zasloff MA. The histopathology of fibrodysplasia ossificans progressiva. An endochondral process. J Bone Joint Surg Am. 1993;75(2):220-230.

4. Pignolo RJ, Baujat G, Brown MA, et al. Natural history of fibrodysplasia ossificans progressiva: cross-sectional analysis of annotated baseline phenotypes. Orphanet J Rare Dis. 2019;14(1):98.

5. Pignolo RJ, Bedford-Gay C, Liljesthrom M, et al. The Natural History of Flare-Ups in Fibrodysplasia Ossificans Progressiva (FOP): A Comprehensive Global Assessment. J Bone Miner Res. 2016;31(3):650656.

6. Pignolo RJ, Durbin-Johnson BP, Rocke DM, Kaplan FS. Joint-specific risk of impaired function in fibrodysplasia ossificans progressiva (FOP). Bone. 2018;109:124-133.

7. Cohen RB, Hahn GV, Tabas JA, et al. The natural history of heterotopic ossification in patients who have fibrodysplasia ossificans progressiva. A study of forty-four patients. J Bone Joint Surg Am. 1993;75(2):215219.

8. Rocke DM, Zasloff M, Peeper J, Cohen RB, Kaplan FS. Age- and joint-specific risk of initial heterotopic ossification in patients who have fibrodysplasia ossificans progressiva. Clin Orthop Relat Res. 1994(301):243-248.

9. Kaplan FS, Zasloff MA, Kitterman JA, Shore EM, Hong CC, Rocke DM. Early mortality and cardiorespiratory failure in patients with fibrodysplasia ossificans progressiva. J Bone Joint Surg Am. 2010;92(3):686-691.

10. Kaplan FS, Xu M, Seemann P, et al. Classic and atypical fibrodysplasia ossificans progressiva (FOP) phenotypes are caused by mutations in the bone morphogenetic protein (BMP) type I receptor ACVR1. Hum Mutat. 2009;30(3):379-390.

11. Shore EM, Xu M, Feldman GJ, et al. A recurrent mutation in the BMP type I receptor ACVR1 causes inherited and sporadic fibrodysplasia ossificans progressiva. Nat Genet. 2006;38(5):525-527. 
12. Bravenboer N, Micha D, Triffit JT, et al. Clinical Utility Gene Card for: Fibrodysplasia ossificans progressiva. Eur J Hum Genet. 2015;23(10).

13. Connor JM, Evans DA. Genetic aspects of fibrodysplasia ossificans progressiva. J Med Genet. 1982;19(1):35-39.

14. Kaplan FS, Pignolo RJ, Shore EM. The FOP metamorphogene encodes a novel type I receptor that dysregulates BMP signaling. Cytokine Growth Factor Rev. 2009;20(5-6):399-407.

15. Kaplan FS, Pignolo RJ, Shore EM. Granting immunity to FOP and catching heterotopic ossification in the Act. Semin Cell Dev Biol. 2016;49:30-36.

16. The Medical Management of Fibrodysplasia Ossificans Progressiva: Current Treratment Considerations. https://www.ifopa.org/updated_ fop_treatment_guidelines_released. Accessed March 17, 2020.

17. Kaplan FS, Pignolo RJ, Al Mukaddam MM, Shore EM. Hard targets for a second skeleton: therapeutic horizons for fibrodysplasia ossificans progressiva (FOP). Expert Opin Orphan Drugs. 2017;5(4):291-294.

18. ClinicalTrials.gov. 2020. https://clinicaltrials.gov/. Accessed March 30, 2020.

19. Ongoing clinical trials in FOP. https://www.ifopa.org/ongoing clinical_trials_in_fop. Accessed March 30, 2020.

20. Hair MS, Peeper JL. The International Fibrodysplasia Ossificans Progressiva Association. Clin Rev Bone Mineral Metab. 2005;3:267269.

21. Kitterman JA, Kantanie S, Rocke DM, Kaplan FS. Iatrogenic harm caused by diagnostic errors in fibrodysplasia ossificans progressiva. Pediatrics. 2005;116(5):e654-661.

22. Bank TW. World Population Prospects: The 2019 Revision. https:// data.worldbank.org/indicator/SP.POP.TOTL. Published 2015. Accessed January 19, 2020.

23. Kaplan FS, Al Mukaddam M, Shore EM. The twenty-seventh annual report of the FOP collaborative research project. FOP Connection. 2019;33(1):1-68. https://d3n8a8pro7vhmx.cloudfront.net/ifopa/ pages/103/attachments/original/1546541800/Annual_Report_ of_FOP_Collaborative_Research_Project_2018_19.pdf?1546541800. Accessed January 19, 2020.

24. Auvin S, Irwin J, Abi-Aad P, Battersby A. The Problem of Rarity: Estimation of Prevalence in Rare Disease. Value Health. 2018;21(5):501-507

25. Teltsch DY, Swain RS, Reynolds MW. Estimation of the prevalence of very rare diseases based on data from specialized treatment centers: approaches for the identification of the reference population. The Evidence Forum. 2014:1-4. https://www.evidera.com/wp-content/ uploads/2015/04/Estimating-the-Prevalance-of-Rare-DiseasesBased-on-Data.pdf.

26. Baujat G, Choquet R, Bouee S, et al. Prevalence of fibrodysplasia ossificans progressiva (FOP) in France: an estimate based on a record linkage of two national databases. Orphanet $J$ Rare Dis. 2017;12(1):123.

27. She D, Zhang K. Fibrodysplasia ossificans progressiva in China. Bone. 2018;109:101-103.

28. Shore EM, Feldman GJ, Xu M, Kaplan FS. The genetics of fibrodysplasia ossificans progressiva. Clin Rev Bone \& Miner Metab. 2005;3:201-204.

29. Zhang W, Zhang K, Song L, et al. The phenotype and genotype of fibrodysplasia ossificans progressiva in China: a report of 72 cases. Bone. 2013;57(2):386-391.

30. Mantick N, Bachman E, Baujat G, et al. The FOP Connection Registry: Design of an international patient-sponsored registry for Fibrodysplasia Ossificans Progressiva. Bone. 2018;109:285-290.

31. Retief, C. Tin Soldiers: Far more than a movie, it's a global call. Daily Maverick Ocober 11, 2019. https://www.dailymaverick.co.za/ article/2019-10-11-tin-soldiers-far-more-than-a-movie-its-a-globalcall/. Accessed September 20, 2020. 